\title{
Temperature effect on growth, and selected parameters of Phaeodactylum tricornutum in batch cultures*
}

\author{
Monika Bojko ${ }^{1}$, Klaudia Brzostowska1, Paulina Kuczyńska¹, Dariusz Latowski1凶, Monika Ol- \\ chawa-Pajor ${ }^{1}$, Weronika Krzeszowiec'ㄹ, Andrzej Waloszek' ${ }^{1}$ and Kazimierz Strzałka1 \\ 1Department of Plant Physiology and Biochemistry, Faculty of Biochemistry, Biophysics and Biotechnology, Jagiellonian University, Kraków, \\ Poland; '2Department of Plant Biotechnology, Faculty of Biochemistry, Biophysics and Biotechnology, Jagiellonian University, Kraków, Poland
}

\begin{abstract}
The effect of optimal and stress temperatures on the growth kinetics of the Phaeodactylum tricornutum CCAP/1055/1 strain (a model diatom with a known genome sequence) in batch cultures was examined. The analysis of the obtained results showed two phases of culture growth. There were significant positive correlations between OD increase of chlorophyll a chlorophyll $c$ and protein concentration at different temperatures. The $F_{v} / F_{m}$ parameter achieved a maximum level on the $6^{\text {th }}$ or $7^{\text {th }}$ day and then decreased to the values registered on the first day of observation. Genetic material undergoes gradual degradation 10 days after inoculation. The size of the cells was invariable.
\end{abstract}

Key words: Phaeodactylum tricornutum, diatoms, chlorophylls, cell size, photosynthesis, Fv/Fm

Received: 31 October, 2013; revised: 09 December, 2013; accepted: 17 December, 2013; available on-line: 30 December, 2013

\section{INTRODUCTION}

The Phaeodactylum tricornutum has been used as a model over several decades to study diatom cell biology, physiology and recently molecular biology and genetics (Martino et al., 2011). Diatoms are the dominant phytoplankton species in the marine environment under nutrient-rich conditions. In freshwater ecosystems diatoms play a major role when high concentrations of nutrients are accompanied with low temperatures. Marine diatoms fix 20 billion tons of carbon per year which corresponds to $40 \%$ of the marine and $20 \%$ of the global net primary production. This immense carbon fixation is even higher than that of the most productive terrestrial ecosystem, the tropical rainforests (Geider et al., 2001). It is known that environmental changes or experimental conditions significantly influence the morphology, physiology and molecular biology of the diatoms. Morphological transformation of the cells was observed as a result of salinity and temperature stress. The composition of the medium, temperature, inoculum size, UV radiation effected fatty acid production and some physiological parameters of photosynthesis. The temperature and light intensity also influenced the level of carbon fixation, the rate of cell division, cell length and vacuole size (Fawley, 1984; Yongmanitchai \& Ward, 1991; Kudo et al., 2000; Liang et al., 2006; Martino et al., 2011). It was observed that size of the cells at 23 to $25^{\circ} \mathrm{C}$ were larger than those which were grown at lower temperature (Fawley, 1984). Temperature stress effected on proportion between morphotype and transformation of cells into the oval type (Mar- tino et al., 2011). Chloroplasts were the largest at temperature above $21^{\circ} \mathrm{C}$. Increase of the growth temperature resulted in increase of carbon fixation by diatioms (Fawley, 1984), eicosa-pentaenoic acid, and optimum culture temperature for fatty acid production were estimated as $21.5^{\circ} \mathrm{C}$ to $23^{\circ} \mathrm{C}$ (Yongmanitchai \& Ward, 1991). Low temperature showed predominance of genes typical for stress pathway (Martino et al., 2011).

Despite wide variety of experimental work on the diatoms and the enormous ecological importance of these organisms, so far no correlation between parameters of diatoms in vitro culture and their biological condition, manifested by, i. a. the concentration of photosynthetic pigments, proteins, cell size, RNA and DNA content, the $\mathrm{Fv}_{\mathrm{V}} / \mathrm{Fm}$ ratio and the optical density $\left(\mathrm{OD}_{405}, \mathrm{OD}_{600}\right)$ was found.

The estimation of the culture conditions, such as its duration and temperature, allowing achievement of diatoms in their optimal stage of development was the goal of our work.

The experiments were performed using the $\mathrm{Ph}$. tricornutum CCAP/1055/1 strain as a model diatom with a known genome sequence.

\section{METHODS}

The Ph. tricornutum CCAP 1055/1 strain was obtained from the Culture Collection of Algae and Protozoa at the Dunstaffnage Marine Laboratory, UK. The diatoms were grown in standard culture conditions in an $\mathrm{f} / 2$ medium (Guillard \& Ryther 1962), suplemented with sodium metasilicate $(3 \%), \mathrm{f} / 2$ vitamins (filter sterilized and added after autoclaving) $1.6 \%$ sea salt (Tropic Marin). $\mathrm{Ph}$. tricornutum cells were previously acclimated 5 to 8 days to the experimental temperature. Aproximetly $500 \mathrm{ml}$ of acclimated inoculum with an optical density $\left(\mathrm{OD}_{600}\right)$ of $0.3-0.4$ was used at the start of $1500 \mathrm{ml}$ the culture. Cells were grown in batch cultures under photoperiod 10:14h D:L with a white light intensity of $40 \mu \mathrm{Em}^{-2} \mathrm{~s}^{-1}$ at optimal temperatures of $15^{\circ} \mathrm{C}$ and $20^{\circ} \mathrm{C}$ (according to CCAP 1055/1 strain data, Scottish Marine Institute, Oban, UK) as well as under stress conditions of $12^{\circ} \mathrm{C}$ and $23^{\circ} \mathrm{C}$. Cultures were shaken several times a week during the light phase to keep cells in suspension and maintain an optimal exchange of gas and nutrients. The

e-mail: dariusz.latowski@uj.edu.pl

* Presented at the 5th Central European Congress of Life Sciences "EUROBIOTECH 2013", Kraków, Poland.

Abbreviations: Chl, chlorophyll; Fv/Fm, maximum photochemical efficiency of PS2; OD, optical density 
observations were individually for each culture at different temperatures. Cultures were analysed in duplicate for each temperature and all experimets were performed in quadruplicate.

Optical density of the cultures was measured at 600 (Yongmanitchai \& Ward 1991) and $405 \mathrm{~nm}$ (Goossens, 2011) with Metertek SP-830 spectrophotometer $(1 \mathrm{~cm}$ standard cuvette).

Chlorophyll fluorescence was measured by a PAM-210 fluorymeter. Before measurement $1 \mathrm{ml}$ of sample (batch culture) was concentrated, transferred to paper and dark - adapted for $15 \mathrm{~min}$. The software generated Fo (minimum) and Fm (maximum) fluorescence values from which Fv/Fm was calculated (Maxwell \&Johnson, 2000).

Protein concentration was measured by Lowry method (1951).

Chlorophyll $a$ and chlorophyll $c$ were extracted in 90\% acetone, with liquid nitrogen cooling. The concentration of chlorophylls was determined with a spectrofotometer (Jasco V-650) and calculated by Jeffrey \& Humphrey method (1975).

Total RNA was isolated in two steps. First, TRI Reagent (Ambion) was used to isolate RNA. Then RNasy Mini Kit (Qiagen) was used to obtain purified RNA from aqueous phase. Electrophoresis were performed in $2 \%$ agarose gel in TAE buffer (Tris/acetic acid, $0.5 \mathrm{M}$ EDTA, $8.5 \mathrm{pH})$ at $80 \mathrm{~V}$.

Measurements of cell length were made on live cells on the $7^{\text {th }}$ and $18^{\text {th }}$ day of culture (culture temperature $12^{\circ} \mathrm{C}$ or $20^{\circ} \mathrm{C}$ ). A rectangular fragment of Parafilm was cut in order to form a well on the glass slides. One or two drops of the culture were put inside Parafilm well and covered with a glass cover slip. To calculate precisely the cell length the images were collected using a Nicon Eclipse TE 200 microscope with a NomarskiDIC prism with a $60 \times$ objective $(60 \times$ LWD $0.52 \mathrm{Ni}$ con, Japan Lens). The microscope was equipped with an Evolution VF Cooled Monochrome Camera (Witkom, Poland). Measurements were performed using Image-Pro Express Version 5.1.0.12. Fifty cells were measured at each temperature both on the $7^{\text {th }}$ and $18^{\text {th }}$ day of culture.

\section{RESULTS AND DISCUSSION}

Analysis of the results demonstrated that temperature had significant effects on the growth kinetics of $\mathrm{Ph}$. tricornutum. Two phases of culture growth were observed (Fig. 1). The faster phase was detected between the $1^{\text {st }}$ and $5^{\text {th }}$ day after inoculation. The second one was slower and was recorded from the $6^{\text {th }}$ till $14^{\text {th }}$ day.

In cultures growing at $20^{\circ} \mathrm{C}$ and $23^{\circ} \mathrm{C}$ the highest chlorophylls and proteins concentration as well as OD were detected on the last day of observation. An analysis of the relation between the parameters shows that in the starting 5 days after inoculation, there was a significant positive correlation between OD increase of chlorophyll a, chlorophyll $c$, and protein concentration, and $\mathrm{F}_{\mathrm{v}} / \mathrm{F}_{\mathrm{m}}$ at different temperatures (Fig. 1 and Fig. 2). It is known that the chlorophyll concentration is strongly dependent of temperature growth. 30\% lower concentration of chlorophyll a per cell volume was detected while temperature decreased from 20 to $10^{\circ} \mathrm{C}$ (Kudo et al., 2000). In our experiments the pattern and strength of correlations
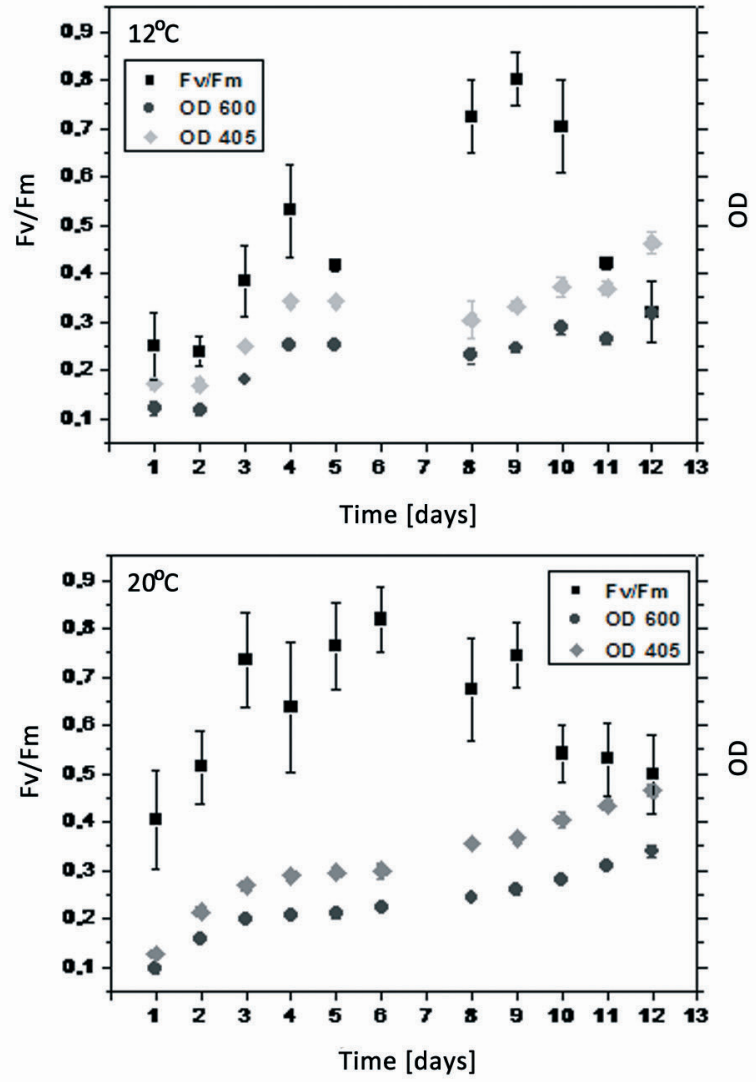
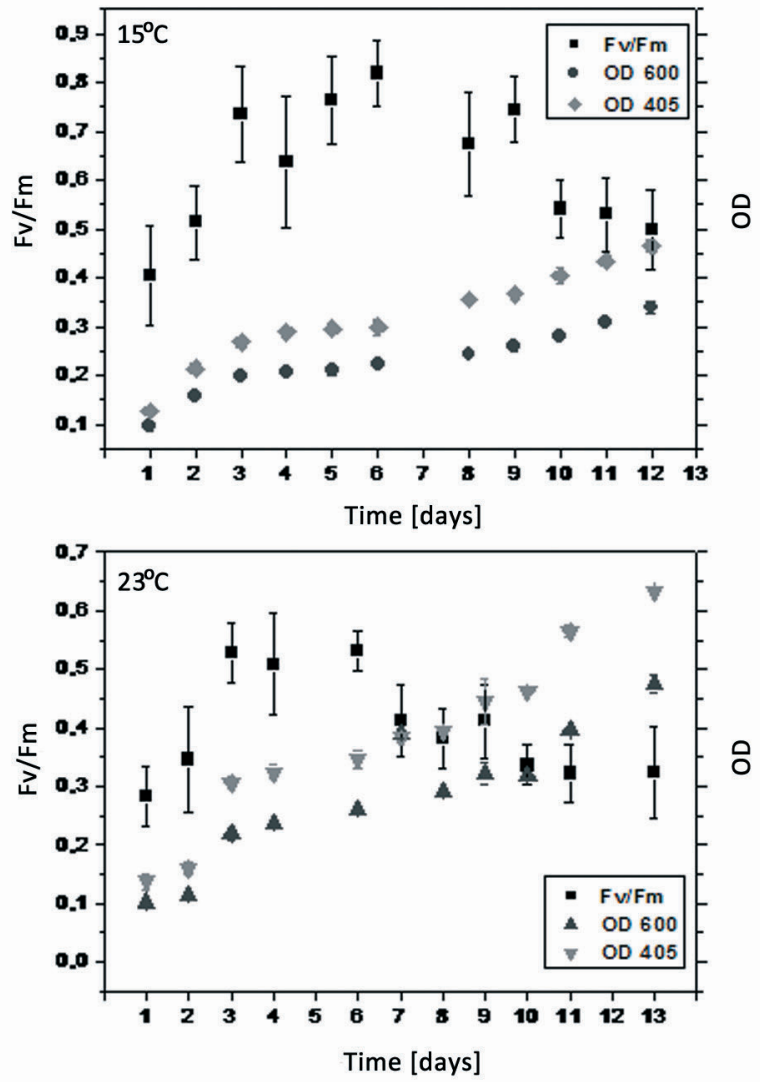

Figure 1. Effect of temperature on OD and Fv/Fm of Phaeodactylum tricornutum in batch culture 

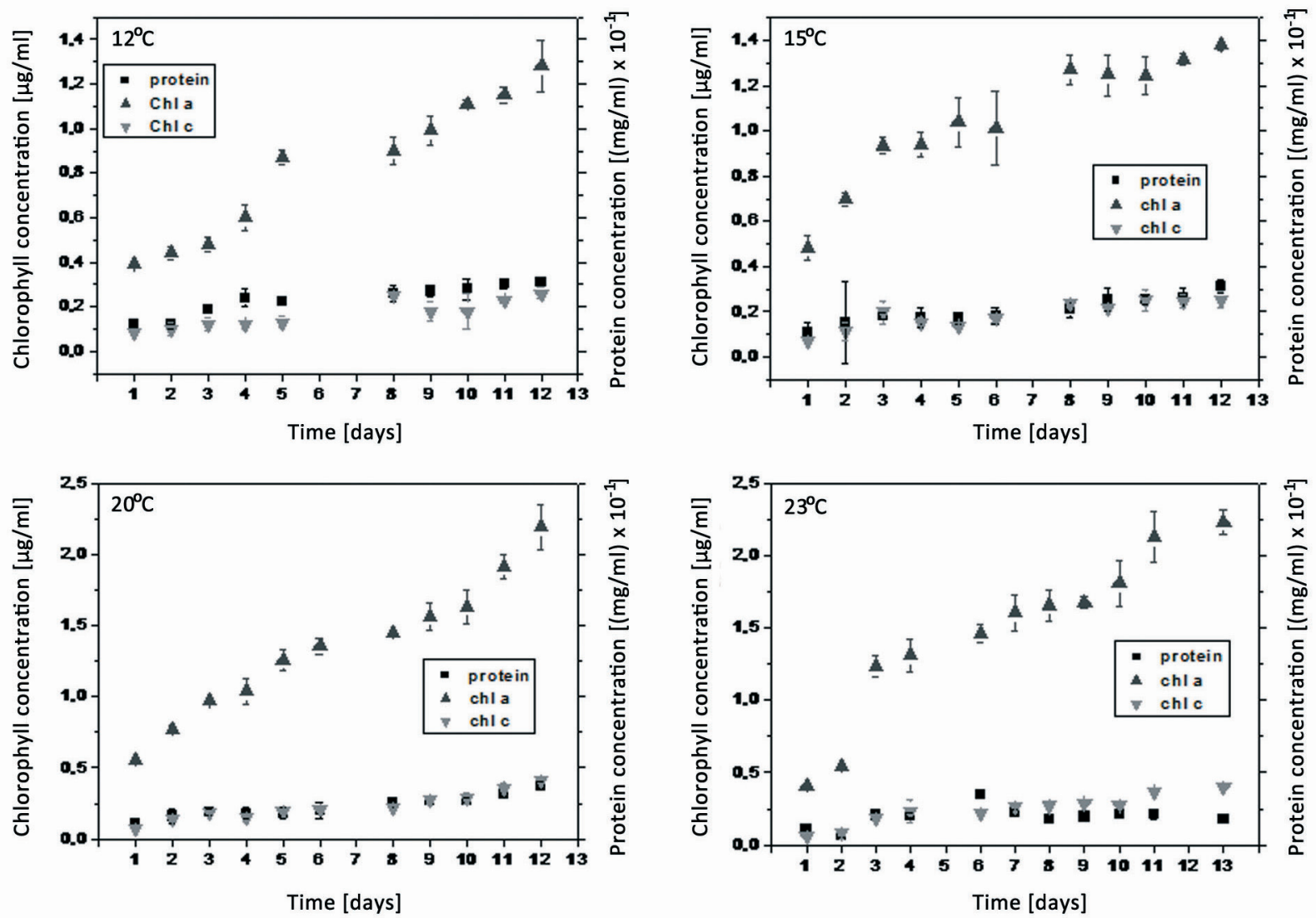

Figure 2. Effect of temperature on chlorophyll a, chlorophyll c, and protein concentration in Phaeodactylum tricornutum batch cultures

varied with temperatures. Several days after inoculation (from $6^{\text {th }}$ till $14^{\text {th }}$ day) chlorophylls and proteins concentrations as well as their OD increased continuously at all temperature growths (Fig. 2).

On the other hand the $\mathrm{F}_{\mathrm{v}} / \mathrm{F}_{\mathrm{m}}$ parameter which provides information on the functionality of PS2 (Lichtenthaler et al., 2005) achieved a maximum level at $6^{\text {th }}$ or $7^{\text {th }}$ day and then decreased to the values registered on the first day of observation. The increase of $\mathrm{Fv} / \mathrm{Fm}$ in the beginning of experiments and stabilization of this parameter after third day after inoculation were observed at $18^{\circ} \mathrm{C}$ (Liang et al., 2006). At the highest temperature $\left(23^{\circ} \mathrm{C}\right)$ the values of this parameter were the lowest. Ge-

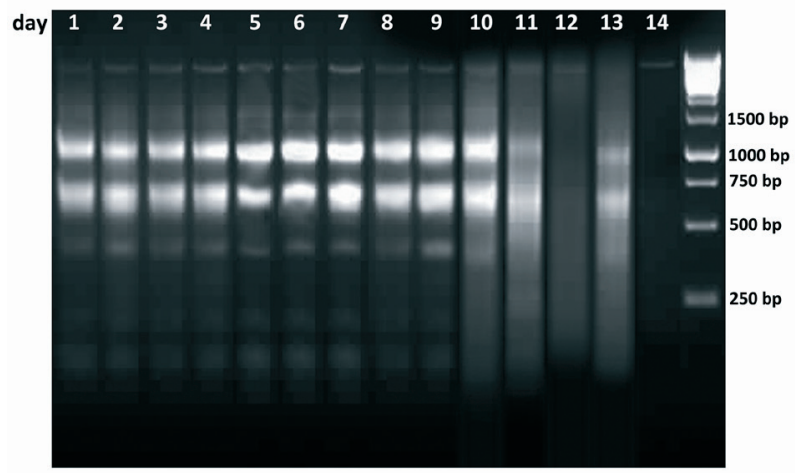

Figure 3. Total RNA isolated over two weeks from Phaeodactylum tricornutum grown at $15^{\circ} \mathrm{C}$.

The right line is the molecular weight marker $1 \mathrm{~kb}$ (Fermentas) netic material (total level of RNA) undergoes a gradual degradation 10 days after inoculation (Fig. 3).

The temperature affects the relative proportions of $P h$. tricornutum morphotype and cell size. There are three types of diatom cells shape: triradiate, fusiform and oval cell. Pt8. ${ }_{6 \mathrm{~F}}$ monoclonal strain (CCAP 1055/1) displayed mainly fusiform cells $(80 \%$ fusiform, $6 \%$ triradiate and $10 \%$ oval) in $19^{\circ} \mathrm{C}$. The decrease on fusiform cells and increase of the oval ones was observed when temperature was changed to lowervalues. This conversion was

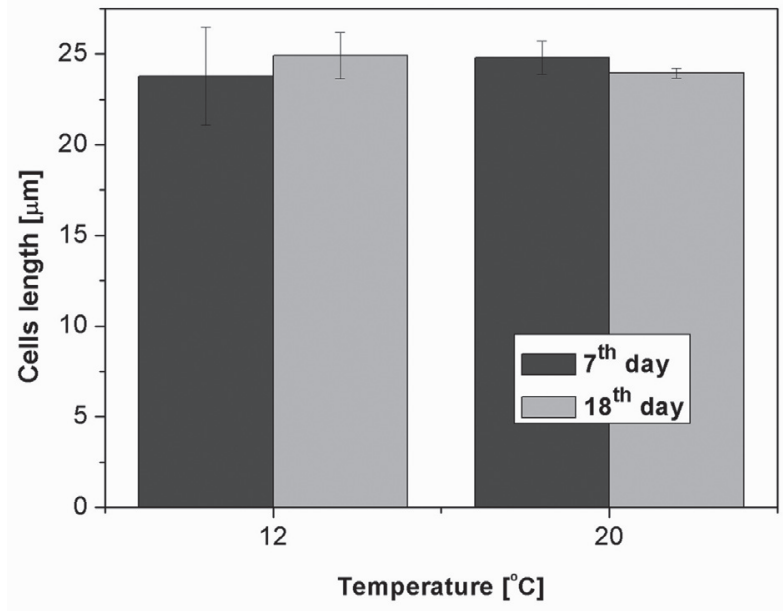

Figure 4. Effect of temperature on Phaeodactylum tricornutum cell length on $7^{\text {th }}$ and $18^{\text {th }}$ day after inoculation. Each value is the average of fifty measurements 
reversible when cells were transferred to higher temperature (Martino et al., 2011). These results cause that we chose two temperatures $\left(12\right.$ and $\left.20^{\circ} \mathrm{C}\right)$ for experiment. In our experiment only fusiform of $\mathrm{Ph}$. tricornutum was observed. The size of cells was invariable (approximately $25 \mu \mathrm{m}$ ) and independent of both observation time and growth temperature (Fig. 4). The same length of fusiform cells was described by Lewin et al. (1958).

All tested parameters clearly shown that the biological conditions of $\mathrm{Ph}$. tricornutum are optimal in the period between $4^{\text {th }}$ and $6^{\text {th }}$ day from inoculation. Both the rate of the culture growth and proteins, RNA or photosynthetic pigments concentration demonstrated the highest values. Similarly, cell size and $\mathrm{Fv} / \mathrm{Fm}$ ratio indicated the best condition of the tested diatoms. Presented results define the best time for applying of $\mathrm{Ph}$. tricornutum CCAP/1055/1 strain, which is commonly used as a model organism in studies of physiology and biochemistry of diatoms.

\section{Acknowledgements}

This work was supported by project No. 2011/01/M/ NZ1/01170.

\section{REFERENCES}

Fawley MW (1984) Effects of light intensity and temperature interaction on growth characteristic of Phaeodactylum tricornutum (Bacillariophyceae). J Phycol 20: 67-72.

Goossens K (2011) Engineering of lipid metabolism in the diatom Phaeodactylum tricornutum Master's dissertation submitted to obtain the degree of Master of Biochemistry and Biotechnology Major Structural Biotechnology and Biochemistry, Academic year 2011-2012.

Jeffrey SW, Humphrey GF (1975) New spectrophotometric equation for determining chlorophyll a, b, c1 and c2 in higher plants, algae and natural phytoplankton. Biochem Physiol Pflan 167: 191-194.

Kudo I, Miyamoto M, Noiri Y, Maita Y (2000) Combined effects of temperature and iron on the growth and physiology of the marine diatom Phaeodactylum tricornutum (Bacillariophyceae). J Physiol 36: 1096-1102.

Liang Y, Beardall J, Heraud P (2006) Effect of UV radiation on growth, chlorophyll fluorescence and fatty acid composition of Phaeodactylum tricornutum and Chaetoceros muelleri (Bacillariophyceae). Phycologia 45: 605-615.

Lichtenthaler HK, Buschmann C, Knapp M (2005) How to correctly determine the different chlorophyll fluorescence parameters and the chlorophyll fluorescence decrease ratio $\mathrm{R}_{\mathrm{Fd}}$ of leaves with the PAM fluorometer. Photosynthetica 43: 379-393.

Lowry OH, Rosebrough NJ, Farr A., Randall R (1951) Protein measurement with the Folin phenol reagent. I Biol Chem 193: 265-227.

Martino AD, Bartual A, Willis A, Meichenin A, Villazán B, Maheswari U, Bowler C (2011) Physiological and molecular evidence that environmental changes elicit morphological interconversion in model diatom Phaeodactylum tricornutum. Protist 162: 462-481.

Maxwell K, Johnson GN (2000) Chlorophyll fluorescence - a practical guide. J Exp Bot 51: 659-668.

Yongmanitchai W, Ward P (1991) Growth of Omega-3 fatty acid production by Phaeodactylum tricornutum under different culture condition. Appl Environ Micriobiol 57: 419-425. 